\title{
Allies or Commitment Devices? A Model of Appointments to the Federal Reserve*
}

\author{
Keith E. Schnakenberg ${ }^{\dagger} \quad$ Ian R. Turner ${ }^{\ddagger} \quad$ Alicia Uribe-McGuire ${ }^{\S}$ \\ January 31,2017
}

\begin{abstract}
We present a model of executive-legislative bargaining over appointments to independent central banks in the face of an uncertain economy with strategic economic actors. The model highlights the contrast between two idealized views of Federal Reserve appointments. In one view, politicians prefer to appoint conservatively biased central bankers to overcome credible commitment problems that arise in monetary policy. In the other, politicians prefer to appoint allies, and appointments are well described by the spatial model used to describe appointments to other agencies. Both ideals are limiting cases of our model, which depend on the level of economic uncertainty. When economic uncertainty is extremely low, politicians prefer very conservative appointments. When economic uncertainty increases, politicians' prefer central bank appointees closer to their own ideal points. In the typical case, the results are somewhere in between: equilibrium appointments move in the direction of politician's preferences but with a moderate conservative bias.
\end{abstract}

${ }^{*}$ The authors would like to especially thank Gary Miller for helpful comments throughout the development of this project, as well as the anonymous reviewers and the editor. All errors are the authors' alone.

† Assistant Professor, Department of Political Science, Washington University in St. Louis. Contact: keschnak@wustl.edu.

$\ddagger$ Corresponding author. Assistant Professor, Department of Political Science, Texas A\&M University. Contact: irturner@tamu.com. I gratefully acknowledge the research support from NSF Grant DGE-1143954.

${ }^{\S}$ Assistant Professor, Department of Political Science, University of Illinois at Urbana-Champaign. Contact: aburibe@illinois.edu 
In the United States, the process of Presidential appointment and Senate confirmation of Federal Open Market Committee (FOMC) members is an important avenue for political influence on monetary policy. Two theoretical traditions inform political scientists' understanding of Federal Reserve appointments. The first tradition holds that politicians face incentives to ex ante commit to low inflation policies and ex post break those commitments to generate short-term improvements in real economic outcomes, e.g., growth and employment (Kydland and Prescott, 1977; Barro and Gordon, 1983). Thus, delegating monetary policy authority to a relatively conservative, independent central bank(er) can serve as a commitment device that allows politicians to credibly commit to low inflation policies thereby mitigating this time-inconsistency problem (Rogoff, 1985; Alesina and Summers, 1993). The second tradition assumes instead that politicians prefer to appoint bankers that agree with them on matters of monetary policy and represents this process using spatial models of appointments (Chang, 2001, 2003; Morris, 2000). ${ }^{1}$ These models are consistent with "the ally principle" which states that politicians seek agents that represent their preferences as closely as possible (Bendor and Meirowitz, 2004).

Both theoretical traditions appear to be consistent with data in important ways. In favor of the credible commitment approach, comparative empirical evidence suggests that countries with independent central banks experience lower levels of inflation (Alesina and Summers, 1993). In favor of the ally approach, empirical studies have provided evidence that the preferences of appointed FOMC governors track those of their appointing parties. ${ }^{2}$ Though the theories may seem to be in tension with one another, we think that they represent a realistic trade-off that politicians face when delegating monetary policy: delegate to an ally and suffer high inflation due to the commitment problem, or appoint conservatively biased central bankers and allow some policy drift. ${ }^{3}$

\footnotetext{
${ }^{1}$ These models are similar to those used for appointments to other agencies (Lewis, 2008) or to the judiciary (Binder and Maltzman, 2009).

${ }^{2}$ See, for example, Adolph (2013); Havrilesky (1988, 1994, 1995); Havrilesky and Gildea (1992); Chappell, Havrilesky and McGregor (1993); Chappell, McGregor and Vermilyea (2004a,b). However, as Adolph (2013) discussed, this finding is also consistent with classic economic models.

${ }^{3}$ Clark and Arel-Bundock (2013) illustrate a complementary trade-off from the central banker's point-of-view: they argue Fed governors must weigh the preferences of their principals, which vary, in order to preserve institutional independence. This ex post trade-off in monetary policy choices generates variation in what appears to be instrumentally-induced partisan bias of the bankers.
} 
Previous scholars have studied the extent of political influence on FOMC appointments, finding mixed results. Some studies have found evidence that FOMC members appointed in times of Republican control pursue tighter (more conservative) monetary policy, in line with the expectations of the partisan model (e.g., Adolph, 2013; Chang, 2003; Havrilesky and Gildea, 1992; Morris, 2000). In contrast, other recent work fails to find significant evidence of partisan FOMC appointments (Eijffinger, Mahieu and Raes, 2015) or finds that partisan effects are present in during the Great Recession but not in other recent eras (Smales and Apergis, 2016). Furthermore, Tempelman (2008) argues that hypotheses about politicization of the Federal Reserve (i.e. the influence of political party as well as the existence of political business cycles) do not stand up well to an analysis restricted to the last quarter of the twentieth century and the beginning of the twenty-first century. ${ }^{4}$ We suggest a possible reason for these mixed results: as economic conditions change, so does the nature of the bargaining process for appointing members of the FOMC. Thus, the system may shift back and forth between periods characterized by a very partisan FOMC appointment process and those characterized by relative preference agreeement among political actors over how to delegate monetary policy. Though the relevant economic processes may be complex, we provide a simple model that characterizes one potential economic variable that may affect this shift: economic uncertainty.

In particular, we develop a model of executive-legislative bargaining over appointments to the Federal Reserve. In our model, the President nominates a central banker that is subject to veto by the Senate. Inflationary expectations in the market then adjust to account for the central banker, and then at some later point the central banker sets monetary policy in response to an economic

\footnotetext{
${ }^{4}$ The research contradicting findings of partisan appointees is limited for our purposes because these were not studies specifically designed to understand Presidential and Congressional preferences over appointees. For instance, these papers pool Board of Governors members with other FOMC members, clouding the results to some degree. However, together they give the impression that findings about political influences on Federal Reserve policy depend critically on time frame and model specification. Similarly, findings in favor of partisan appointments have limitations: Chang (2003) shows that actual appointee ideology is correlated with a predicted ideology derived from a theoretical model, making it difficult to ascertain the influence or reach of the input variables. Adolph (2013) relies on career background as a proxy for monetary preferences rather than a direct revealed preference measure, but these background characteristics may be differentially desirable to different Presidents for reasons other than ideology. Our point is not to endorse one set of findings but to illustrate that there may be variation that is not well explained by either idealized view of appointments.
} 
shock. The central banker must consider a trade-off between ensuring lower inflation, thereby leading to greater variability in unemployment, and setting inflation to compensate for possible economic shocks, lowering the variability in unemployment.

Our results show that when economic uncertainty is low all politicians agree that the appointment should be used as a commitment device. Hence, both the President and Senate prefer a relatively conservative central banker. However, as economic uncertainty increases political actors prefer more liberal central bankers and the optimal appointment depends more critically on each actors' preferences. Thus, as economic uncertainty rises the appointment process becomes more politically contentious and political actors prefer central bankers to more closely approximate their personal monetary policy preferences. This dynamic is driven by the fact that politicians are risk averse and by the relationship between ex ante uncertainty and ex post outcome variability with different appointees. Liberal central bankers reduce variability in unemployment at the cost of higher, and more variable, inflation. As a politician's monetary policy preferences become more liberal they care more about variability in unemployment relative to variability in inflation. So when economic uncertainty is high and politicians are relatively liberal they are more willing to accept increases in expected inflation in exchange for a reduction in unemployment variability, which leads to a preference for a more liberal central bank appointee. In contrast, when economic uncertainty is very low there is low variability in outcomes. Since liberal appointees cannot decrease expected unemployment there is no reason for any politicians to accept higher expected inflation, which leads to agreement on appointing a perfectly conservative central banker.

Recent work has also emphasized the role of uncertainty in monetary policy and appointments. Ainsley (Forthcoming) presents a novel model of central bank appointments in which the ideology of the central bank appointee responds to economic uncertainty. Our model differs from Ainsley's in two ways. First, uncertainty is conceptualized much differently in our model than in Ainsley. Economic uncertainty in our model generates discretion for the central banker to increase inflation above market expectations. In contrast Ainsley models a situation in which central bankers have no additional information about the economy and respond to uncertainty because of asymmetric risk 
preferences. Thus, our model is designed to highlight the effects of time inconsistency while Ainsley's highlights the effect of central bankers' attitudes toward risk. Second, we include a model of inter-institutional bargaining over central bankers, while Ainsley focuses on the optimal central banker for a single policymaker that holds a monopoly over appointments. Thus, our model complements Ainsley (Forthcoming) and provides an alternative mechanism through which economic uncertainty may affect appointments. ${ }^{5}$

Adolph (2013) also provides results that suggest that the logic underlying conservative central bank appointments as credible commitment devices (e.g., Rogoff, 1985) and preference-driven spatial appointment models (e.g., Chang, 2001, 2003) can coexist. Specifically, he shows that while political actors may always prefer a central banker relatively more conservative than they are, the level of conservatism (inflation-averseness) is decreasing as the political players become more liberal. While our model generates a similar result, ${ }^{6}$ we build on it by providing comparative statics with respect to economic uncertainty that show how appointments approach one idealized process or the other. In addition, we also incorporate the Senate as a veto player and focus on how economic variables alter the nature of the bargaining between the two actors. ${ }^{7}$

In the next section we present our model of central bank appointments. We then characterize how central banker ideology affects policy choice and economic outcomes. The following section analyzes optimal central bank appointments from the perspective of the President and Senate. The final analysis section presents the main results of the paper, which illustrate how the nature of the economic environment structures the political appointment process. The final section provides a substantive discussion of these results, including empirical implications, and concludes. ${ }^{8}$

\footnotetext{
${ }^{5}$ Despite these differences, our model and Ainsley's (Forthcoming) produce similar comparative statics with respect to the economic uncertainty parameters. This suggests that the main predictions emphasized in this paper may be robust to the consideration of very different models of economic uncertainty.

${ }^{6}$ In particular, our Proposition 3 below corresponds to Adolph's result.

${ }^{7}$ This is illustrated in Example 1 below.

${ }^{8}$ All proofs of formal results are relegated to the appendix.
} 


\section{A Model of Appointments to the Federal Reserve}

To formalize the appointment process to the Federal Reserve we develop a non-cooperative game with a President, a representative Senator, a Central Banker, and a Wage Setter. We define the preferences of the actors by relying on a set of familiar economic assumptions, which are similar to several papers in the central banks literature (e.g., Alesina, Roubini and Cohen, 1997; Keefer and Stasavage, 2003). The economy is characterized by a baseline rate of unemployment, denoted by $\bar{y}>0$ and a slope parameter $\alpha>0$ that quantifies the trade-off between unemployment and inflation. Unemployment is generated by the following function:

$$
y(\pi, w)=\bar{y}-\alpha(\pi-w)-\varepsilon,
$$

where $\pi$ denotes the level of inflation, $w$ is the nominal wage, and $\varepsilon$ is a stochastic shock to output distributed around mean 0 with finite variance $\sigma^{2}$. Equation 1 captures the intuition from classic economic models: unemployment can be driven to an unnaturally low level if the rate of inflation is higher than nominal wages. Politicians have an incentive to strategically drive unemployment down by creating surprise inflation and therefore delegation to an independent central banker that is relatively conservative (inflation-averse) may be desirable to solve the credible commitment problem this incentive creates. The optimal level of central banker conservatism will hinge on these economic considerations.

In particular, a key parameter that drives many of the results that follow is the variability of economic shocks $\sigma$, which we refer to as economic uncertainty. The higher is $\sigma$, the less agents know about what the state of the economy will be in a future period in which monetary policy is chosen. Exogenous increases in $\sigma$ capture shocks to the economy due to economic crises, global commodity shocks (e.g., oil prices), and other similar, relatively unpredictable events. In contrast, lower values of $\sigma$ represent relatively stable economic environments in which there is lower uncertainty about future inflation. Since uncertainty due to $\sigma$ is resolved by the time the Central Banker sets inflation levels, economic uncertainty is not necessarily equivalent to observed variability in 
outcomes. For instance, an extremely liberal Central Banker will set inflation high enough to compensate for negative shocks to output, so we would observe low variability in unemployment even for high values of $\sigma$ but inflation may be highly variable. An extremely conservative Central Banker will set inflation to zero under all circumstances, so we would observe no variability in inflation but high variability in unemployment. In other words, variability in outcomes is a function of uncertainty and policy factors.

With the unemployment function in hand we now characterize the preferences of the President, Senator, and Central Banker. These preferences are given by the following utility function,

$$
u_{i}(\pi, y(\pi, w))=-\pi^{2}-b_{i} y^{2} \text { for } i \in\{P, S, C\}
$$

Each actor has the same target rates of inflation and unemployment, which are normalized to 0 , and differ only by the relative weights they place on inflation and unemployment represented by $b_{i} \geq 0$. We refer to $b_{i}$ as the actor $i$ 's ideal point or monetary policy position where lower levels of $b_{i}$ denote a more conservative or inflation-averse ideal point whereas a higher $b_{i}$ denotes a liberal or more employment-focused ideal point.

The preferences of the Wage Setter are given by the following utility function,

$$
u_{W}=-(\pi-w)^{2}
$$

Equation 3 ensures that nominal wages will be set equal to expected inflation in equilibrium.

Prior to any actions there is a status quo Central Banker with ideal point $b^{S Q}$ who remains in office until replaced by a newly appointed Central Banker. We understand $b^{S Q}$ to represent the common understanding of how current members of the FOMC will implement monetary policy in the absence of a new appointment. ${ }^{9}$ The timing of the game, then, is as follows.

\footnotetext{
${ }^{9}$ Other models of appointments, such as Krehbiel (2007), conceptualize the process as a move-the-median game. These models represent the fact that, when an appointment is to an existing voting body, the appointer can only move the outcome so far. For instance, when the President makes an appointment to fill one Supreme Court vacancy, the new median will be somewhere in the closed interval connecting the fourth and fifth most liberal justices among the eight still remaining on the court since an appointment outside of that interval will result in one of those two justices
} 
1. The President selects a nominee by proposing $b>0$.

2. The Senator accepts or rejects the nominee:

(a) If $S$ accepts the nominee, then $b_{C}=b$.

(b) If $S$ rejects the nominee, then $b_{C}=b^{S Q}$.

3. The Wage Setter chooses $w$.

4. The output shock, $\varepsilon$, is realized.

5. The Central Banker sets the level of inflation, $\pi$.

\section{Equilibrium Inflation and Unemployment}

We utilize subgame perfect Nash equilibrium (SPNE) as our solution concept, which we find through backward induction. In the final stage of the game the Central Banker sets the rate of inflation, $\pi$. Thus, the Central Banker takes an action solving the following problem:

$$
\pi^{*}\left(b_{c}, w\right)=\underset{\pi}{\arg \max }\left[-\pi^{2}-b_{C}(\bar{y}-\alpha(\pi-w)-\varepsilon)^{2}\right] .
$$

Essentially, the Central Banker chooses the inflation rate that maximizes her expected utility. Solving this problem for the Central Banker leads to the following best response function,

$$
\pi^{*}\left(b_{C}, w\right)=\frac{b_{C} \alpha(w \alpha+\bar{y}-\varepsilon)}{b_{C} \alpha^{2}+1} .
$$

Notice that the best response $\pi^{*}\left(b_{C}, w\right)$ depends on $w$ : the Wage Setter's choice of wage level. Thus, to fully characterize the subgame following approval (or rejection) of the central bank ap-

becoming the median. The same logic applies to the FOMC, but we choose to ignore the committee component for two reasons. First, the move-the-median approach results in multiple equilibria because the President and Senate are indifferent over a large number of appointments that result in the same median. Ignoring this aspect essentially selects what we feel would be the most reasonable equilibrium in the move-the-median game, which is the one in which players act as if appointments are pivotal. Other equilibria would not be robust to small probabilities of random events such as unexpected deaths or retirements. Second, our model leads to less ambiguity about the reversion point, or status quo. In a move-the-median game, the status quo point may be anywhere in the median interval, though in equilibrium the players would have a common conjecture about the outcome of not making an appointment. Thus, it is simpler to abstract from this reasoning and start with the common conjecture, which is the point labeled $b^{S Q}$ below. 
pointment we solve the Wage Setter's problem, given by:

$$
w^{*}\left(b_{C}\right)=\underset{w}{\arg \max }\left[-\mathbb{E}\left[\left(w-\pi^{*}\left(b_{C}\right)\right)^{2}\right]\right] .
$$

At the solution, wages are simply set equal to the expected level of inflation. Thus, the wage rate in equilibrium is $w^{*}\left(b_{C}\right)=b_{C} \bar{y} \alpha$. We can substitute this expression into the solution for $\pi^{*}\left(b_{C}, w\right)$, which yields the following result.

Lemma 1. In equilibrium, a Central Banker with monetary policy ideal point $b_{C}$ sets the level of inflation according to the following equation:

$$
\pi^{*}\left(b_{C}\right)=\frac{\alpha b_{C}\left(\alpha^{2} \bar{y} b_{C}+\bar{y}-\varepsilon\right)}{\alpha^{2} b_{C}+1} .
$$

The pair $\left(w^{*}\left(b_{C}\right), \pi^{*}\left(b_{C}\right)\right)$ is an equilibrium to the subgame involving the Wage Setter's and Central Banker's decisions. The equilibrium to this subgame depends on $b_{C}$ and therefore induces preferences for the President and Senator regarding the optimal central bank appointment. We can now characterize how economic outcomes are affected according to the preferences of the Central Banker. Proposition 1 describes how these economic outcomes-inflation and unemploymentdepend on these preferences.

Proposition 1. The preferences of the Central Banker affect economic outcomes as follows:

1. Expected inflation is both higher and more variable as the Central Banker becomes more liberal.

2. Expected unemployment levels are independent of the Central Banker but become less variable as the Central Banker becomes more liberal.

The conclusions in Proposition 1 are straightforward. Central Bankers who place less emphasis on low inflation relative to low unemployment will be more tempted to generate inflation, therefore expected inflation is higher for these actors. Moreover, while conservative Central Bankers tend 
to moderate the effects of output shocks, liberal Central Bankers utilize shocks to generate lower unemployment, thereby creating higher levels of variability in the rate of inflation.

The inability of the Central Banker to lower expected unemployment is a result of the standard rational expectations argument: wage setters anticipate the effect of a liberal central banker on expected inflation and incorporate this information into wage contracts, so that the average effect of monetary policy on unemployment is null. However, since the central banker is, at times, able to take advantage of output shocks, employment is more stable for more liberal central bankers.

\section{Equilibrium Central Bank Appointments}

With the equilibrium behavior of the Wage Setter, the Central Banker, and how the preferences of a given appointed Central Banker affect inflation and unemployment in hand we can now finish constructing the SPNE of the appointments game by characterizing the equilibrium appointment strategy of the President and the equilibrium approval strategy of the Senator. Given the strategies characterized in the previous section and the fact that both the President and the Senator must act prior to the realization of the output shock $\varepsilon$, their equilibrium strategies are based on expected utility. In particular, the expected squared level of inflation, as characterized in Lemma 1, is given by:

$$
\mathbb{E}\left[\pi^{*}\left(b_{C}\right)^{2}\right]=\operatorname{Var}\left[\pi^{*}\left(b_{C}\right)\right]+\mathbb{E}\left[\pi^{*}\left(b_{C}\right)\right]=\frac{\alpha^{2} \sigma^{2} b_{C}^{2}}{\left(\alpha^{2} b_{C}+1\right)^{2}}+b_{C}^{2} \bar{y}^{2} \alpha^{2}
$$

Similarly, the expected squared level of unemployment is given by:

$$
\mathbb{E}\left[y(\pi, w)^{2}\right]=\frac{\sigma^{2}}{\left(\alpha^{2} b_{C}+1\right)^{2}}+\bar{y}^{2}
$$

Substituting these expectations into the utility functions for the President and the Senator yields the following expected utility:

$$
U_{i}\left(b_{C}\right)=\mathbb{E}\left(u_{i}\left(\pi, y(\pi, w) \mid b_{C}\right)=-\frac{\left(\alpha^{2} b_{C}^{2}+b_{i}\right)\left(\bar{y}^{2}\left(\alpha^{2} b_{C}+1\right)^{2}+\sigma^{2}\right)}{\left(\alpha^{2} b_{C}+1\right)^{2}}, i \in\{S, P\}\right.
$$


From this expected utility expression, we can conclude that there is a unique ideal appointee for the President and for the Senator. Furthermore, the ideal appointee for each actor is strictly more conservative than that actor. Thus, induced preferences over appointees take on a spatial structure, but it is one in which neither of the actors prefer to appoint an agent that exactly represents their own interests. The preferences of the actors therefore violate the ally principle, which holds in a wide range of other models of delegation (Bendor, Glazer and Hammond, 2001; Bendor and Meirowitz, 2004). ${ }^{10}$

Proposition 2. The President and Senator each have an ideal Central Bank appointee and both actors prefer to delegate to a Central Banker who is strictly more conservative than themselves.

A best response for the Senator involves accepting nominees for appointment such that the Senator's expected utility given the appointee's monetary policy ideology (weakly) outweighs the utility the Senator would receive from rejecting the nominee and retaining the status quo, i.e., $U_{S}(b) \geq U_{S}\left(b^{S Q}\right)$. This is akin to the Senator using a threshold acceptance strategy, which can also be represented by an equivalent "acceptance set." The Senator will approve a Central Bank nominee with monetary policy ideology $b$ if and only if the nominee is in the Senator's acceptance set $A_{S}$ (i.e., $b \in A_{S}=\left\{b: U_{S}(b) \geq U_{S}\left(b^{S Q}\right)\right\}$ ). The President knows what nominees are acceptable to the Senator and which are not and therefore maximizes his expected utility subject to the constraint provided by $A_{S}$. Since $b^{S Q} \in A_{S}$ and the President is indifferent between choosing a status quo nominee and being rejected, we assume that the President chooses $b^{S Q}$ in the event that no element of $A_{S}$ is preferred to the status quo. The full SPNE to this game therefore is the solution to a standard spatial bargaining game (Romer and Rosenthal, 1978; Ferejohn and Shipan, 1990) with these induced preferences. In the next section, we characterize the predictions that arise from the equilibrium to the game.

\footnotetext{
${ }^{10}$ We use the term ally principle in the same way as Bendor and Meirowitz (2004), who take the term to mean that "the boss picks the most ideologically similar agent as delegatee." We do not mean to imply, however, that violation of the ally principle in this case runs counter to the logic of their model. In fact, a departure from the ally principle is to be expected when interpreting this model in light of Bendor and Meirowitz's (2004) results since the agent does not fully control unemployment. Thus, when we discuss our model in relation to the ally principle, we are comparing our results to other theoretical models (e.g. Chang $(2001,2003))$ in which the assumptions are consistent with the ally principle.
} 


\section{Economic Uncertainty and the Optimal Central Banker}

When are central bank appointments characterized by a tendency to appoint allies? When do politicians instead use central bankers as commitment devices to keep inflation low? To answer these questions we provide a series of results that speak directly to how politicized the appointments process is conditional on the economic environment. The first result concerns the relationship between the positions of the President and Senator and that of the equilibrium nominee. Although Proposition 2 predicts that the President and Senator both prefer a nominee more conservative than themselves the following result confirms that the ideal position of nominees is positively correlated with the positions of the President and Senator.

Proposition 3. The ideological position of the equilibrium Central Bank appointment is weakly increasing in the positions of the President and the Senator.

The President and the Senator prefer a central bank appointee that is more conservative than they are (Proposition 2), but how conservative the equilibrium appointment will be relative to the political actors bargaining over the appointment depends on the ideological positioning of the President and Senator. As Adolph (2013) has noted, the prediction of Proposition 3 holds both in the spatial models of Chang $(2001,2003)$ and in the economic models like that of Rogoff (1985). Notice, however, that Proposition 3 merely shows that as the President and the Senator become more liberal, the Central Banker appointed in equilibrium could become more liberal as well. The main insight here is that as the ideal points of the actors bargaining over the appointment move toward more liberal monetary policy preferences, the ideal appointment becomes (weakly) more liberal. This result does not, in itself, provide insight into when and why the appointments process is more or less politicized, as we would expect to see in a purely ideological appointments model. Combined with the following results, however, we do begin to generate insight into the effect of economic uncertainty on the political appointment process.

As described informally in the previous section, the relationship between politicians' preferences and equilibrium appointees observed in this model depends critically on uncertainty in 
the economy. Since large variations in unemployment can occur with very conservative central bankers, risk averse politicians will strike a balance between delegating to conservative central bankers and appointing allies. This dynamic leads to the following result.

Proposition 4. In equilibrium, Central Bank appointments become more liberal as economic uncertainty increases.

Combined with the previous result, Proposition 4 presents two limiting cases for equilibrium appointments. As economic uncertainty approaches zero, i.e., $\sigma \rightarrow 0$, appointments become perfectly conservative. All politicians prefer appointees that are fully focused on inflation and do not care at all about unemployment. Conversely, as economic uncertainty rises, i.e., $\sigma \rightarrow \infty$, individual behavior resembles a politicized appointment process in which both the President and the Senator prefer ideological allies. The second observation follows from the fact that, for any finite $\sigma$, Proposition 2 implies that politicians prefer appointees that are strictly more conservative than themselves. Thus, since preferred appointments are strictly increasing in economic uncertainty, $\sigma$, the politician's ideal appointment approaches their own position from below as this uncertainty becomes large. The combination of the limiting cases provided by Propositions 3 and 4 lead to the main insight of this paper.

Proposition 5. As $\sigma$ goes to zero, the game converges to one in which the President and Senator mutually prefer a perfectly conservative central banker $\left(b_{c}=0\right)$. As $\sigma$ goes to infinity, the game converges to one in which the President and Senator each prefer central bankers with preferences identical to their own $\left(b_{C}=b_{i}, i \in\{P, S\}\right)$.

Proposition 5 provides a testable restriction on the strategies of the President and the Senator that can be contrasted with traditional spatial models of central bank appointments (e.g., Chang, 2001, 2003; Morris, 2000). In particular, Proposition 5 suggests that, in less stable economic environments, the political actors involved in bargaining over the appointed central banker-the President and the Senator-will prefer an appointee that more closely resembles their respective ideal monetary policy ideologies while in other, more certain, environments they will be more 
aligned in their collective preference for a conservative central banker. Thus, when uncertainty is high the results predict that we should observe higher levels of conflict between ideologically divergent executives and legislative actors (as in Chang, 2003; Morris, 2000, for example). When uncertainty is lower we should observe a more consensual process characterized by a common value, relatively conservative, appointment (as in Rogoff, 1985, for example).

Taken together, Propositions 2-5 describe a link between economic conditions and political conflict over Fed appointments. To conceptualize the predictions of our model, consider the effects of exogenous shocks to economic uncertainty. Such shocks may arise from economic crises, supply shocks to commodities such as oil, natural disasters, or any number of other events. The theory predicts that positive shocks to economic uncertainty will cause monetary nominations to become more hotly contested, with liberal politicians preferring much more doveish appointees relative to their conservative colleagues. In contrast, periods of low economic uncertainty should generate more consensus on nominees, with liberal and conservative politicians mostly agreeing on relatively conservative nominees. This dynamic also suggests that the effect of economic uncertainty on the bargaining process itself alters the traditional understanding of Senate confirmation as a constraint on Presidential appointments. Rather than a simple comparison of ideal points relative to status quo outcomes, the presence of economic environmental concerns creates a situation in which the Senate only constrains Presidential appointments in particular environments. Example 1 illustrates this for several levels of economic uncertainty, $\sigma$.

Example 1. To help illustrate how economic uncertainty changes the bargaining between the President and the Senate over FOMC appointments, we present an illustrative example. Let $\bar{y}=1$ and $\alpha=1$, and assume that $b^{S Q}=\frac{1}{2}, b_{S}=1$, and $b_{P}=2$. In a standard spatial bargaining game, the President would be constrained by the Senate in this scenario. The President's preferred nominee would be located at his ideal point, which is farther from the Senate than the Status Quo. The expectation under the standard model is that the nominee would be selected at the Senate's indifference point, $b_{C}=1 \frac{1}{2}$. Below, we show how the value $\sigma$ changes the bargaining game. We will 
consider three possible values of $\sigma:^{11}$

- Let $\sigma=\frac{1}{4}$. The President's ideal nominee is $b_{C} \approx .092$. Approving this nominee yields $S$ an expected utility of around -1.06 compared to around -1.28 for maintaining the status quo. Thus, the Senate will approve the President's ideal nominee and the President can act as if he is unconstrained.

- Let $\sigma=2$. The President's ideal nominee is $b_{C} \approx .81$. Approving this nominee yields $S$ an expected utility of around -3.67 compared to -3.47 for maintaining the status quo. Thus, the Senate will not approve the President's ideal nominee (i.e. the President faces a binding constraint of confirmation). The equilibrium appointment is $b_{C} \approx .55$, which leaves the Senate indifferent between approving the nominee and maintaining the status quo.

- Let $\sigma=20$. The President's ideal nominee is $b_{C} \approx 1.88$. Approving this nominee yields $S$ an expected utility of around -223.42 compared to around -223.47 for maintaining the status quo. Thus, the Senate will approve the President's ideal nominee.

In the separation of powers literature, spatial bargaining models provide insights into when Senate confirmation provides a binding constraint on Presidential appointments (e.g., Krehbiel, 2007; Moraski and Shipan, 1999; Rohde and Shepsle, 2007). When the President's ideal nominee is also preferable to the status quo from the perspective of the decisive Senator, confirmation is not a binding constraint. Otherwise, the President chooses a less-than-ideal nominee that improves his payoff but leaves the decisive Senator indifferent between accepting the new nominee and maintaining the status quo. This logic also holds in our model, but the inclusion of economic factors complicates the story considerably. In most spatial bargaining models, the presence or absence of binding constraints on the President depend only on the relative ideological locations of the President, the Senate, and the status quo. As Example 1 illustrates, a variety of conclusions are

\footnotetext{
${ }^{11}$ All three examples are easily solved by substituting the provided parameter values into the expected utility expression in Equation 7 and performing the typical operations for maximizing expected utility. For the sake of brevity, we avoid showing extensive calculations, though supplementary Mathematica code is available upon request.
} 
possible in our model for different values of $\sigma$ even while holding the preferences of the President and pivotal Senator fixed.

Example 1 illustrates that as economic variables change the same configuration of preference and status quo points can yield significantly different bargaining dynamics. None of the scenarios in Example 1 mirror the expectations for a standard spatial bargaining model. For very low uncertainty, the President is unconstrained because both agents prefer to appoint a relatively conservative central banker to fight inflation. The President is also unconstrained when uncertainty is very high because both agents prefer a relatively liberal central banker to reduce unemployment variability. ${ }^{12}$ However, for moderate levels of economic uncertainty, there is conflict between the political actors over the preferred central bank appointment. The President is forced to adjust his central bank nominee to satisfy the binding constraint of Senate confirmation. Thus, the example shows how predictions of interest from separation of powers appointment models may change significantly in the case of monetary policy as economic conditions change.

\section{Conclusion}

In this paper we have highlighted two conflicting incentives faced by politicians when delegating monetary policy and shown how economic conditions help predict which incentive will dominate. On one hand, politicians are incentivized to delegate to conservative bankers in order to credibly commit to low inflation policies. On the other hand, politicians may prefer allies whose monetary preferences would be more similar to their own. Our model predicts that the tendency to appoint allies should dominate more when economic uncertainty is very high, since appointing more doveish central bankers reduces levels of variability in unemployment. In contrast, when economic uncertainty is low, politicians are less concerned with potential variability in outcomes so credible commitment is a stronger incentive and conservative appointees should be more common. Since

\footnotetext{
${ }^{12}$ The example also shows that, when uncertainty is high, the Senate may accept nominees that are further away from their own preferences (and from their ideal nominee) than are the status quo. This occurs because induced preferences over nominees need not be symmetric.
} 
preferences over nominees depend on economic conditions, spatial bargaining models must be amended to reflect the ways in which the main predictions change as the economy changes.

Additionally, we provide one hypothesis to explain the mixed results regarding partisan influence over monetary policy in the existing literature. Our theory predicts that the effects of political variables on monetary outcomes will vary based on the level of economic uncertainty faced by the relevant actors. This is consistent with work that suggests that partisan effects are relevant for some eras more than others (e.g., Smales and Apergis, 2016). Ultimately, more work needs to be done to flesh out when and why political factors may influence economic outcomes through appointment channels. This article represents one such attempt to provide a reasonable theoretical hypothesis to guide future inquiry.

\section{References}

Adolph, Christopher. 2013. Bankers, Bureaucrats, and Central Bank Politics: The Myth of Neutrality. New York, NY: Cambridge University Press.

Ainsley, Caitlin. Forthcoming. "The Politics of Central Bank Appointments.” Journal of Politics .

Alesina, A. and L. H. Summers. 1993. "Central bank independence and macroeconomic performance: some comparative evidence.” Journal of Money, Credit and Banking 25(2):151 - 162.

Alesina, Alberto, Nouriel Roubini and Gerald D. Cohen. 1997. Political cycles and the macroeconomy. The MIT press.

Barro, Robert and David Gordon. 1983. "A Positive Theory of Monetary Policy in a Natural Rate Model.” The Journal of Political Economy 91(4):589-610.

Bendor, Jonathan and Adam Meirowitz. 2004. "Spatial models of delegation." American Political Science Review 98(02):293-310. 
Bendor, Jonathan, Ami Glazer and Thomas Hammond. 2001. “Theories of Delegation.” Annual Review of Political Science 4:235 - 269.

Binder, Sarah A. and Forrest Maltzman. 2009. Advice and Dissent: The Struggle to Shape the Federal Judiciary. Brookings Institution Press.

Chang, Kelly H. 2001. "The president versus the Senate: Appointments in the American system of separated powers and the Federal Reserve." Journal of Law, Economics, and Organization 17(2):319-355.

Chang, Kelly H. 2003. Appointing central bankers: The Politics of Monetary Policy in the United States and the European Monetary Union. Cambridge University Press.

Chappell, Henry W., Jr., Rob Roy McGregor and Todd Vermilyea. 2004a. Committee Decisions on Monetary Policy: Evidence from Historical Records of the Federal Open Market Committee. Cambridge, MA: MIT Press.

Chappell, Henry W., Jr., Rob Roy McGregor and Todd Vermilyea. 2004b. "Majority Rule, Consensus Building, and the Power of the Chairman: Arthur Burns and the FOMC.” Journal of Money, Credit, and Banking 36(3):407 - 422.

Chappell, Henry W., Thomas Havrilesky and Rob Roy McGregor. 1993. "Partisan Monetary Policies: Presidential Influence Through The Power of Appointment." Quarterly Journal of Economics 108(1):185 - 218 .

Clark, William Roberts and Vincent Arel-Bundock. 2013. "Independent But Not Indifferent: Partisan Bias In Monetary Policy At The Fed." Economics \& Politics 25(1):1-26.

Eijffinger, Sylvester, Ronald Mahieu and Louis Raes. 2015. "Hawks and Doves at the FOMC." CentER Discussion Paper 2015-013:Tilburg: Economics.

Ferejohn, John and Charles Shipan. 1990. "Congressional influence on bureaucracy." Journal of Law, Economics, and Organization 6(1):1-20. 
Havrilesky, Thomas and John A. Gildea. 1992. "Reliable and unreliable partisan appointees to the Board of Governors." Public Choice 73(4):397-417.

Havrilesky, Thomas M. 1988. "Monetary Policy Signaling from the Administration to the Federal Reserve.” Journal of Money, Credit, and Banking 20(1):83 - 101.

Havrilesky, Thomas M. 1994. “Outside Influences on Monetary Policy: A Summary of Recent Findings." Contemporary Economic Policy 12(1):46 - 51.

Havrilesky, Thomas M. 1995. The Pressures on American Monetary Policy. 2 ed. Boston, MA: Kluwer.

Keefer, Philip and David Stasavage. 2003. "The Limits of Delegation: Veto Players, Central Bank Independence, and the Credibility of Monetary Policy." American Political Science Review 97(3):407- 423 .

Krehbiel, Keith. 2007. "Supreme Court appointments as a move-the-median game." American Journal of Political Science 51(2):231-240.

Kydland, Finn E. and Edward C. Prescott. 1977. "Rules Rather Than Discretion: The Inconsistency of Optimal Plans.” Journal of Political Economy 85(3):473-91.

Lewis, David E. 2008. The Politics of Presidential Appointments: Political Control and Bureaucratic Performance. Princeton, NJ: Princeton University Press.

Milgrom, Paul and Chris Shannon. 1994. "Monotone comparative statics.” Econometrica: Journal of the Econometric Society 62(1):157-180.

Moraski, Bryon J. and Charles R. Shipan. 1999. "The Politics of Supreme Court Nominations: A Theory of Institutional Constraints and Choices." American Journal of Political Science 43(4):1069-1095.

Morris, Irwin L. 2000. Congress, the president, and the Federal Reserve : the politics of American monetary policy-making. University of Michigan Press, Ann Arbor, MI. 
Rogoff, Kenneth. 1985. "The optimal degree of commitment to an intermediate monetary target." The Quarterly Journal of Economics 100(4):1169-1189.

Rohde, David W. and Kenneth A. Shepsle. 2007. "Advising and Consenting in the 60-Vote Senate: Strategic Appointments to the Supreme Court.” The Journal of Politics 69(03):664-677.

Romer, Thomas and Howard Rosenthal. 1978. "Political resource allocation, controlled agendas, and the status quo." Public Choice pp. 27-43.

Smales, Lee A. and Nick Apergis. 2016. "The Influence of FOMC Member Characteristics on the Monetary Policy Decision-making Process." Journal of Banking \& Finance 64:216-231.

Tempelman, Jerry H. 2008. "The Depoliticization of Monetary Policy." Business Economics 43(2):16-22.

\section{Appendix}

Proof of Lemma 1. Recall the Central Banker solves the following problem:

$$
\max _{\pi}\left[-\pi^{2}-b_{C}(\bar{y}-\alpha(\pi-w)-\varepsilon)^{2}\right] .
$$

The first order condition for a maximum is:

$$
-2 \pi-b_{C} \alpha(\bar{y}-\alpha(\pi-w)-\varepsilon)=0 .
$$

Solving the first order condition and substituting in $w^{*}\left(b_{C}\right)$ yields the best response given by Equation 6. The second order condition is met since $u_{C}$ is concave. Therefore, this is a best response for the Central Banker and $\pi^{*}\left(b_{C}\right)$ is the inflation rate chosen in a SPNE.

Proof of Proposition 1. Claim (1) follows easily from the derived strategies. The expected value 
of inflation is $b_{c} \bar{y} \alpha$ which is clearly increasing in $b_{C}$. The variance of inflation is

$$
\frac{\alpha^{2} \sigma^{2} b_{C}^{2}}{\left(\alpha^{2} b_{C}+1\right)^{2}}
$$

which is increasing in $b_{C}$ since

$$
\frac{\partial}{\partial b_{C}} \frac{\alpha^{2} \sigma^{2} b_{C}^{2}}{\left(\alpha^{2} b_{C}+1\right)^{2}}=\frac{2 \alpha^{2} \sigma^{2} b_{c}}{\left(\alpha^{2}+1\right)^{2}}>0 .
$$

Since $E\left(w^{*}\left(b_{C}\right)-\pi^{*}\left(b_{C}\right)\right)=0$ for any $b_{C}$ and $E(\varepsilon)=0$, the expected value of unemployment is simply $\bar{y}$ for all $b_{C}$. The variance of $y\left(\pi^{*}\left(b_{C}\right), w^{*}\left(b_{C}\right)\right)$ is

$$
\frac{\sigma^{2}}{\left(\alpha^{2} b_{C}+1\right)^{2}}
$$

which is strictly decreasing in $b_{C}$, proving claim (2).

Proof of Proposition 2. We will show that there exists one local maximum to $U_{i}$ which lies in the open interval $\left(0, b_{i}\right)$ for any $b_{i}>0$. The first order condition is

$$
\begin{aligned}
\frac{\partial U_{i}}{\partial b_{C}} & =\frac{2 \alpha^{2}\left(\alpha^{2} b_{C}^{2}+b_{i}\right)\left(\bar{y}^{2}\left(\alpha^{2} b_{C}+1\right)^{2}+\sigma^{2}\right)}{\left(\alpha^{2} b_{C}+1\right)^{3}}-\frac{2 \alpha^{2} \bar{y}^{2}\left(\alpha^{2} b_{C}^{2}+b_{i}\right)}{\alpha^{2} b_{C}+1} \\
& -\frac{2 \alpha^{2} b_{C}\left(\bar{y}^{2}\left(\alpha^{2} b_{C}+1\right)^{2}+\sigma^{2}\right)}{\left(\alpha^{2} b_{C}+1\right)^{2}} \\
& =-\frac{2 \alpha^{2}\left(\alpha^{6} \bar{y}^{2} b_{C}^{4}+3 \alpha^{4} \bar{y}^{2} b_{C}^{3}+3 \alpha^{2} \bar{y}^{2} b_{C}^{2}+b_{C}\left(\bar{y}^{2}+\sigma^{2}\right)-\sigma^{2} b_{i}\right)}{\left(\alpha^{2} b_{C}+1\right)^{3}}=0
\end{aligned}
$$

Since the denominator and the term $2 \alpha^{2}$ must be strictly greater than zero, the solution to the first order condition must be a root to the quartic equation in the numerator:

$$
\alpha^{6} \bar{y}^{2} b_{C}^{4}+3 \alpha^{4} \bar{y}^{2} b_{C}^{3}+3 \alpha^{2} \bar{y}^{2} b_{C}^{2}+b_{C}\left(\bar{y}^{2}+\sigma^{2}\right)-\sigma^{2} b_{i}=0 .
$$


We can re-write this expression as

$$
b_{C}=g\left(b_{C}\right)=b_{i} \cdot \frac{\sigma^{2}}{\bar{y}^{2}\left(\alpha^{2} b_{C}+1\right)^{3}+\sigma^{2}} .
$$

Thus, the solution to our first-order condition is a fixed point of the function $g(\cdot)$. Since the fraction in Equation 11 is always less than $1, g$ is bounded above by $b_{i}$. Since $g$ is also strictly positive, $g$ is a continuous function mapping the interval $\left[0, b_{i}\right]$ onto itself. By Brouwer's fixed point theorem, there exists a fixed point of $g$ on this interval. By the arguments above, the fixed point is on the interior of this interval. Since $U_{i}$ is strictly concave, this fixed point is a maximum of $U_{i}$ and is unique.

Lemma 2. For any parameter $\theta$, if $U_{S}$ satisfies increasing differences ${ }^{13}$ for $\left(b_{C}, \theta\right), A_{S}$ is weakly increasing in $\theta$ in the strong set order. ${ }^{14}$

Proof: Let $\bar{\theta}>\underline{\theta}$ and denote $\overline{A_{S}}$ and $\underline{A_{S}}$ denote the set $A_{S}$ when the parameter $\theta$ is set equal to $\bar{\theta}$ and $\underline{\theta}$, respectively. We consider three cases: (1) there is no $b_{C}^{\prime} \neq b^{S Q}$ such that $U_{i}\left(b_{C}^{\prime}, \underline{\theta}\right)=U_{i}\left(b^{S Q}, \underline{\theta}\right)$; (2) there exists such a $b_{C}^{\prime}$, and $b_{C}^{\prime}>b^{S Q}$; and (3)there exists such a $b_{C}^{\prime}$, and $b_{C}^{\prime}>b^{S Q}$. If there does not exist $b_{C}^{\prime}$ such that $U_{i}\left(b_{C}^{\prime}, \theta\right)=U_{i}\left(b^{S Q}, \theta\right)$, then $\underline{A_{S}}=\left[0, b^{S Q}\right]$. Since $\overline{\left.A_{S}\right)}$ must be an interval including $b^{S Q}$, we have $\overline{A_{S}} \geq_{s} \underline{A_{S}}$.

Now assume there exists a $b_{C}^{\prime}$ such that $U_{i}\left(b_{C}^{\prime}, \underline{\theta}\right)=U_{i}\left(b^{S Q}, \underline{\theta}\right)$. If $b_{C}^{\prime}>b^{S Q}$, then $\underline{A_{S}}=\left[b_{C}^{\prime}, b^{S Q}\right]$. In this case, we must show that, for any $b_{C}^{\prime \prime}<b_{C}^{\prime}, b_{C}^{\prime \prime} \notin \overline{A_{S}}$. By increasing differences, ${ }^{15}$

$$
\begin{array}{r}
U_{S}\left(b_{C}^{\prime}, \underline{\theta}\right)-U_{S}\left(b_{C}^{\prime \prime}, \underline{\theta}\right)>0 \Rightarrow U_{S}\left(b_{C}^{\prime}, \bar{\theta}\right)-U_{S}\left(b_{C}^{\prime \prime}, \bar{\theta}\right) \geq 0 \\
U_{S}\left(b^{S Q}, \underline{\theta}\right)-U_{S}\left(b_{C}^{\prime}, \underline{\theta}\right)=0 \Rightarrow U_{S}\left(b^{S Q}, \bar{\theta}\right)-U_{S}\left(b_{C}^{\prime}, \bar{\theta}\right) \geq 0 .
\end{array}
$$

\footnotetext{
${ }^{13} \mathrm{~A}$ function $f(x, \theta)$ satisfies increasing differences for $(x, \theta)$ if the incremental return, $f(x, \cdot)-f\left(x^{\prime}, \cdot\right)$, is weakly increasing in the parameter, $\theta$.

${ }^{14}$ The strong set order is denoted $\geq_{s}$. When the choice set is a subset of the real line as in this paper and $S^{*}$ and $S^{o}$ are intervals, we will have $S^{*} \geq_{s} S^{o}$ provided that the end-points of $S^{*}$ are greater than or equal to the end-points of $S^{o}$.

${ }^{15}$ This statement is an application of the single-crossing condition, which is implied by increasing differences.
} 
Hence, $U_{S}\left(b^{S Q}, \bar{\theta}\right) \geq U_{S}\left(b_{C}^{\prime}, \bar{\theta}\right)>U_{S}\left(b_{C}^{\prime \prime}, \bar{\theta}\right)$, which implies that $b_{C}^{\prime \prime} \notin \overline{A_{S}}$. Since $\overline{A_{S}}$ must be an interval including $b^{S Q}$, this implies that $\overline{A_{S}} \geq{ }_{S} \underline{A_{S}}$.

Finally, if $b_{C}^{\prime}>b^{S Q}$, then $\underline{A_{S}}=\left[b^{S Q}, b_{C}^{\prime}\right]$. In this case, we must show that $b_{C}^{\prime} \in \overline{A_{S}}$. By increasing differences,

$$
U_{S}\left(b_{C}^{\prime}, \underline{\theta}\right)-U_{S}\left(b^{S Q}, \underline{\theta}\right)=0 \Rightarrow U_{S}\left(b_{C}^{\prime}, \bar{\theta}\right)-U_{S}\left(b^{S Q}, \bar{\theta}\right) \geq 0
$$

which implies that $b_{C}^{\prime} \in \overline{A_{S}}$. The argument in Case 2 shows that there is no point in $\overline{A_{S}}$ smaller than $b^{S Q}$.

we will use the following result, which follows from the monotone selection theorem of Milgrom and Shannon (1994): ${ }^{16}$

Monotone Selection Theorem (Milgrom and Shannon (1994)): Let $X \subseteq \mathbb{R}$ be the set of all possible choices of $x$ and $\Theta \subseteq \mathbb{R}$ be the set of possible values of a parameter $\theta$. Let $f: X \times \Theta \rightarrow \mathbb{R}$. If $S: \Theta \rightarrow 2^{X}$ is nondecreasing and $f$ satisfies the single-crossing condition for $(x, \theta)$, then every selection $x^{*}(\theta)$ from $\arg \max f(x, \theta)$ is monotone nondecreasing in $\theta$.

Proof of Proposition 3: Using the theorem of Milgrom and Shannon (1994), it is sufficient to show that $U_{P}(b)$ satisfies single-crossing for $\left(b, b_{P}\right)$ and for $\left(b, b_{S}\right)$ and that $A_{S}$ is nondecreasing in $b_{P}$ and $b_{S}$. Since $b_{S}$ does not enter $U_{P}(b)$, so $U_{P}(b)$ satisfies single-crossing for $\left(b, b_{S}\right)$ since the cross-partial derivative of $U_{P}(b)$ with respect to $b$ and $b_{S}$ is zero. Similarly, since $U_{S}\left(b_{C}\right)$ does not depend on $b_{P}, A_{S}$ is non-decreasing in $b_{P}$. To show that $U_{P}(b)$ satisfies single-crossing for $\left(b, b_{P}\right)$, note that

$$
\frac{\partial U_{P}}{\partial b_{C} \partial b_{P}}=\frac{2 \alpha^{2} \sigma^{2}}{\left(\alpha^{2} b_{C}+1\right)^{3}}>0
$$

which shows that the increasing differences condition is satisfied, implying that the single-crossing is met. Since, by the same argument, $U_{S}\left(b_{C}\right)$ satisfies single-crossing for $\left(b_{C}, b_{S}\right)$, Lemma 2 establishes that $A_{S}$ is nondecreasing in $b_{S}$, completing the proof.

\footnotetext{
${ }^{16}$ This is Theorem 4' in Milgrom and Shannon (1994). Their result is stated for more general multidimensional problems and requires introducing concepts that we have not defined above, so we restate it for the special case of one-dimensional choice sets and parameters and using the notation introduced above.
} 
Proof of Proposition 4. By the arguments above, we need to show that $U_{i}$ satisfies single crossing for $\left(b_{C}, \sigma\right)$ when $b_{C}$ is in the interval $\left(0, b_{i}\right)$. Note that

$$
\frac{\partial U_{i}}{\partial b_{C} \partial \sigma}=\frac{4 \alpha^{2} \sigma\left(b_{i}-b_{C}\right)}{\left(\alpha^{2} b_{C}+1\right)^{3}}
$$

which is strictly positive given that $b_{C}<b_{i}$. Thus, $U_{i}$ satisfies increasing differences (therefore single-crossing) for $\left(b_{C}, \sigma\right)$, completing the proof.

Proposition 5. By Equation 11 in the proof of Proposition 2, the ideal appointment of each agent $i$ is equal to

$$
b_{i} \cdot \frac{\sigma^{2}}{\bar{y}^{2}\left(\alpha^{2} b_{C}+1\right)^{3}+\sigma^{2}} \text {. }
$$

We have

$$
\lim _{\sigma \rightarrow 0} b_{i} \cdot \frac{\sigma^{2}}{\bar{y}^{2}\left(\alpha^{2} b_{C}+1\right)^{3}+\sigma^{2}}=0
$$

and

$$
\lim _{\sigma \rightarrow \infty} b_{i} \cdot \frac{\sigma^{2}}{\bar{y}^{2}\left(\alpha^{2} b_{C}+1\right)^{3}+\sigma^{2}}=b_{i} \lim _{\sigma \rightarrow \infty} \frac{\sigma^{2}}{\bar{y}^{2}\left(\alpha^{2} b_{C}+1\right)^{3}+\sigma^{2}}=b_{i} .
$$

Furthermore, Proposition 4 shows that every agent's ideal appointment is increasing in $\sigma$. Thus, as $\sigma$ goes to zero, the game approaches one with perfectly conservative appointments and as $\sigma$ gets large the game monotonically approaches the spatial model of appointments in which agents seek appointees at their own ideal point. 